\title{
Epistemic and Mediational Suitability of Tasks Designed in a Mobile Learning Context
}

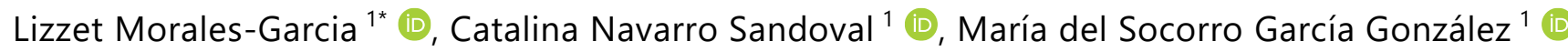 \\ ${ }^{1}$ Autonomous University of Guerrero, MEXICO
}

Received 29 October 2021 - Accepted 23 January 2022

\begin{abstract}
The aim of this research is to propose indicators of epistemic and mediational suitability to assess tasks designed in a mobile learning context, using theoretical and methodological elements of the onto-semiotic approach (OSA) and the SAMR model (substitution, augmentation, modification, and redefinition). With these indicators, 110 tasks designed by two Mexican teachers are evaluated, for the teaching of the natural number in primary education. Some results indicate that the situation-problems addressed the meanings of numerical sequence, operational, ordinal, and measure, and that $56 \%$ of the tasks were located at the substitution level. Some implications derived from the research are that the mathematical content can be complemented by including other representations of the natural number and that the design of tasks that are positioned at the modification and redefinition levels should be encouraged. The foregoing serves as a basis for the design and assessment of mobile content for the natural number concept.
\end{abstract}

Keywords: epistemic suitability, mediational suitability, mobile learning, natural number

\section{INTRODUCTION}

Education systems worldwide face the challenge of incorporating information and communication technologies (ICT) into mathematics curricula, given their potential to be used by teachers in the classroom (Homa-Agostinho \& Oliveira-Groenwald, 2020). There are different trends for the development and implementation of ICT in education, and in particular, mobile learning is gaining strength in recent years, due to the massification of mobile devices in the population (Gómez \& Badia, 2016). Interest in these mobile technologies as emerging and innovative tools has grown in the last decade (Benali \& Ally, 2020) and involves, in general terms, "the integration of mobile devices in teaching and learning" (Grant, 2019, p. 1).

There are different positions on the definition of mobile learning (e.g., Brazuelo \& Gallego, 2014; Crompton, 2013b; Grant, 2019) and mobile device (e.g., Aguilar \& Puga, 2015; Crompton, 2013a). Appropriately, in this research mobile learning is defined as "learning through multiple contexts, through social and content interactions, using personal electronic devices" (Crompton, 2013b, p. 4). This definition includes three important aspects of the term. On the one hand, it involves the diversity of contexts where learning can occur, for example, at home, school, and the outdoors. This is without ruling out interactions between students, or between students and the teacher. It also references the use of personal electronic devices, it being understood that a mobile device is "any personal and portable technological device that could be used in the mathematics classroom, including devices such as laptops, smartphones, and tablets" (Aguilar \& Puga, 2015, p. 178).

In systematic reviews of trends in mobile learning research, its potential to aid in education is shown (e.g., Bano et al., 2018; Diacopoulos \& Crompton, 2020; Lai, 2019; Liu et al., 2021; Yildiz et al., 2020), as well as its main challenges (Benali \& Ally, 2020). In Crompton and Burke (2020), it was reported that $46 \%$ of the time mobile devices are used to replicate activities that can be performed without technology. Crompton et al. (2017) reported that most of the studies were carried out at the primary education level. Research has also been interested in understanding the effect that mobile learning has on student learning (Talan, 2020). 


\section{Contribution to the literature}

- Proposal of indicators of epistemic suitability to assess the mathematical content on natural numbers included in tasks designed for mobile devices.

- Proposal of indicators of mediational suitability to assess the level of integration of a technological resource in the design of tasks for mobile devices.

- Assessment of the epistemic and mediational suitability of tasks designed for a mobile learning context.

Particularly, the use of mobile devices for the teaching-learning of mathematics is an emerging area of research, which is expanding rapidly (Borba et al., 2016) due to its potential to transform mathematics education along with the implementation of attractive educational environments, which can enhance student motivation and learning (Kyriakides et al., 2015). Likewise, these devices have the ability to expand the frontiers of mathematical instruction (Borba et al., 2016) by proposing other contexts where teaching-learning can be developed. However, in order to achieve their integration in the school context, it is necessary to implement better strategies for the adoption of mobile devices. It is important to support teachers given that the absence of knowledge on how to incorporate these technologies can influence their teaching practice (Gómez \& Badia, 2016).

Research on mobile learning is diverse. In primary education, algebra standards, numbers and operations, geometry, data analysis, and probability are the most frequent in research (Crompton \& Burke, 2015). In the standard numbers and operations, mobile applications such as: Mathemagical Oracle (Navarro et al., 2018), A.L.E.X (Kyriakides et al., 2015), TouchCounts (Sinclair et al., 2015), Mati-Tec (Rivero \& Suarez, 2017), and Show and Tell (Ingram et al., 2015) among others, have been proposed. The results suggest that gaming applications are also promising as a tool for the teaching-learning of mathematics (Kyriakides et al., 2015).

For example, in Navarro et al. (2018), it was found that with Mathematical Oracle, students were motivated to perform mathematical exercises thereby impacting the improvement of mental calculation and the understanding of verbal mathematical problems. Whereas, with A.L.E.X (Kyriakides et al., 2015) the children showed emotions of surprise and enthusiasm when using it in the school context. Likewise, applications such as TouchCounts (Sinclair et al., 2015) provided models to work on the ordinal and cardinal meaning of the number, and in the case of Show and Tell (Ingram et al., 2015) it was found that the level and quality of students' commitment to interacting and solving mathematical problems in this application were high. In general, the positive impact of mobile applications for the teaching-learning of this standard is clear.

On the other hand, there is research where the perception that teachers have about the integration of mobile learning is reported (e.g., Handal et al., 2015; Ingram et al., 2015). However, research on uses and potentialities that could be the basis for the implementation of mobile devices is limited in Mathematics Education (Borba et al., 2016; Kyriakides et al., 2015). In this regard, Brazuelo and Gallego (2014) pointed out the need to promote the design of mobile educational content and the preparation of teachers as a key element for the real integration of mobile technologies for educational purposes. This coincides with what was mentioned by Sung et al. (2016), that the existence of research to support teachers with the adoption of mobile technology in their teaching practice is limited.

On the other hand, the onset of the COVID-19 pandemic represented a change in the way mathematics classes are now taught (e.g., Castro et al., 2020; Cervantes-Barraza, 2021), making the use of technology in the school environment no more than considered an option previously to become a necessity for teachers at all educational levels, particularly in primary education. Therefore, the knowledge of mathematics teachers about the different technologies and the design of their own mobile educational content is a challenge they are currently facing.

In mathematics education, a line of research is focused on the design, implementation, and evaluation of formative interventions in the teaching of mathematics, whose purpose is to optimise the process of instruction associated with a specific mathematical concept (e.g., Breda \& Lima, 2016; Posadas \& Godino, 2021). From this line of research, the construct of didactic suitability is used as a tool to organize the reflection of the teacher oriented towards the assessment and improvement of their teaching practice (Godino et al., 2017 , 2019). In this sense, the indicators included in each of the facets of didactic suitability constitute a guide for analysis and systematic reflection that provides criteria for the progressive improvement of teaching-learning processes, from the teaching experienced by the teachers themselves (Godino et al., 2017). We consider that, from this theoretical position the problem related to the design and evaluation of mobile content developed by the teachers themselves can be addressed, on a specific mathematical concept (Borba et al., 2016; Brazuelo \& Gallego, 2014; Kyriakides et al., 2015; Sung et al., 2016). For this reason, the objective of this research was to propose indicators of epistemic and mediational 

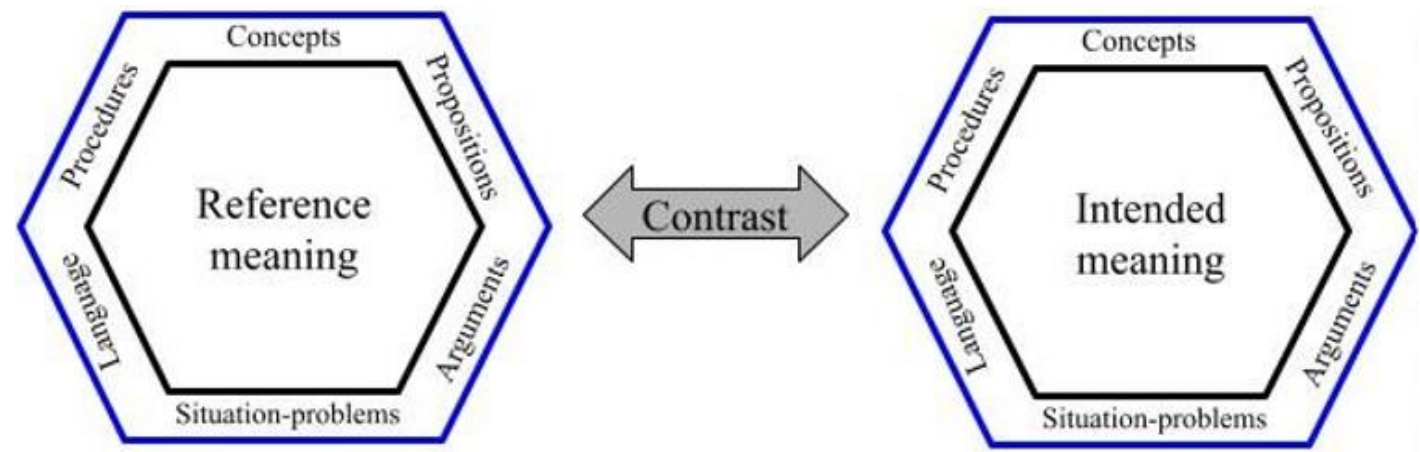

Figure 1. Elements of epistemic suitability

suitability to assess the mathematical content on natural numbers and the level of integration of a technological resource in the design of tasks for mobile learning.

This view allows for the laying of the foundations to guide the design and the assessment of mobile educational content, in addition to the possibility of issuing judgments to assess the tasks designed that are based on the mathematical objects involved and the technological resource used in the design.

\section{THEORETICAL ELEMENTS}

The onto-semiotic approach (OSA), according to Godino (2017), is a modular theoretical system that addresses the problems related to the teaching-learning of mathematics, considering the facets: epistemic, cognitive, affective, interactional, ecological, and mediational. In this approach, mathematical activity is considered a human activity focused on the resolution of certain kinds of problem situations (Godino et al., 2020), and for its study, specific theoretical and methodological tools are available, which allow its analysis at the micro and macro level. One of those tools is didactic suitability, understood as:

The degree to which an instructional process (or part of it) meets certain characteristics that allow it to be qualified as optimal or adequate to achieve adaptation between the personal meanings achieved by students (learning) and the institutional meanings intended or implemented (teaching), taking into account the circumstances and resources available (environment) (Godino et al., 2020, p. 11).

This construct and its decomposition into partial suitability (epistemic, cognitive, affective, mediational, interactional, and ecological) allows the passage from an explanatory didactic to a normative didactic (Godino, 2013) that can guide an instruction process to achieve its improvement. In this research, the notions of epistemic and mediational suitability are used, whose components and indicators are explained in the following sections.

\section{Epistemic Suitability}

Epistemic suitability is defined as "the degree of representativeness of the institutional meanings implemented or intended, with respect to a reference meaning" (Godino, 2013, p. 116) and for its analysis, there are indicators of suitability (Breda et al., 2018; Godino, 2013) where characteristics are presented on mathematical objects that allow for qualifying an instruction process or part of it, as optimal or adequate.

The application of this construct to the field of technology-mediated education has been reflected in research where the epistemic and didactic suitability of educational videos (Beltrán-Pellicer et al., 2018; Santos, 2018), fragments of films and television series in mathematics (Beltrán-Pellicer et al., 2018) among other topics, was analysed. In these researches, the notion of reference meaning played a central role, since it allowed for the reconstruction of a global or holistic meaning of the mathematical object from the specialised literature on the subject, to establish criteria of epistemic suitability typical of the concept studied, which serve as a guide for the assessment of an instruction process in general or of parts of the process, for example, tasks designed with mobile technology.

On the other hand, the notion of intended meaning allows for the identification and analysis of the primary objects and mathematical practices that are put into play when it is intended to teach a mathematical concept using epistemic configuration (Font \& Godino, 2006). In general terms, the contrast between both meanings allows for the assessment of epistemic suitability (Figure 1 ). In this research it was used to assess tasks designed on mobile devices.

\section{Reference meaning and indicators of epistemic suitability of the natural number}

The reference meaning is focused on the systematic analysis of the literature for the identification of the several meanings of the objects and its articulation into a global meaning. This meaning is considered as the reference population of situation-problems (Godino et al., 2017). According to the literature, six meanings of the natural number can be distinguished: numerical sequence, cardinal, ordinal, symbolic, operational, and measure (Alcalde Esteban et al., 2014; Cid et al., 2003; Rico et al., 2008; Rico, 2019). They are understood as follows: 
Table 1. Indicators of epistemic suitability

Component $\quad$ Indicators

Situation-problems Situation-problems are presented that promote the use of the natural number as a numerical sequence, cardinal, ordinal, operational, symbolic, and measure (Alcalde Esteban et al., 2014; Cid et al., 2003; Rico, 2019; Rico et al., 2008).

Language The use of the different representations of the natural number is promoted:

Symbolic: Use of the symbols $0,1,2,3,4,5,6,7,8$, and 9 or $1^{\text {st }}, 2^{\text {nd }}, 3^{\text {rd }}, \ldots$ in its ordinal meaning; Verbal:

Utilize cardinal numerical words (one, two, three, ...) or ordinal numeric words (first, second, or third) to refer to natural numbers

Manipulative material: Use, abacus, Cuisenaire strips, multi-base blocks, among other materials to represent natural numbers;

Graph: use of the number line, point configurations or numerical tables to represent natural numbers (Rico et al., 2008).

Rules (concepts, procedures, and propositions)

Arguments

Relations

Situations in which it must be argued are promoted.

Situations are presented to move between the different representations of the natural number (symbolic, verbal, manipulative material, and graphic).

- Number sequence. Consider the use of the natural number to indicate the order for reciting or writing the sequence of natural numbers. For example, tasks where it is asked to recite and/or complete the number sequence from 1 to 100 .

- Cardinal. Partnered with the use of the number to indicate how many elements there are in a set. For example, indicate the number of beads on a necklace.

- Ordinal. Numbers are used to indicate the position of an object in an ordered set. For example, when asked to indicate the position in which a car arrives in a car race.

- Symbolic. In this case, numbers are used as labels to identify objects. For example, the numbers on the shirts of football players.

- Operational. The use of numbers to perform arithmetic operations is highlighted. For example, determine the result of $10+7$.

- Measure. Among other respects, the use of numbers to indicate how much a person or object measures.

In each of these meanings, a conglomerate of primary objects (situation-problems, language, procedures, concepts, propositions, and arguments) is activated that give specific information of the partial meaning of the natural number. In this sense, for the proposal of indicators of epistemic suitability (Table 1), the review of the literature for the identification of the meaning of the natural number was carried out in the first moment, and subsequently, with this information the indicators of epistemic suitability of Godino (2013) were adapted for the case of the natural number. The extended version of this reconstruction is in Morales-Garcia and Navarro (2021).

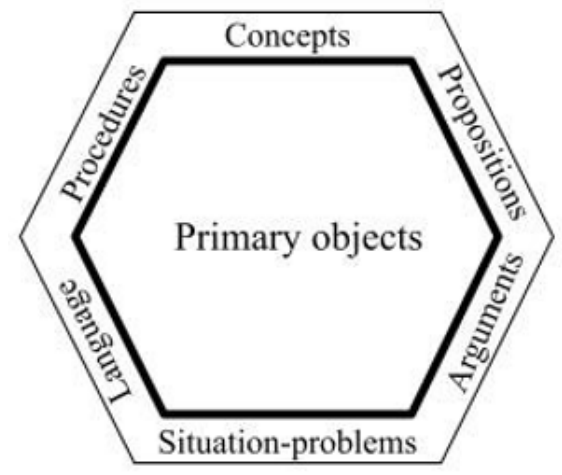

Figure 2. Epistemic configuration

\section{Considerations for task analysis: Intended meaning}

In the analysis of the designed tasks, the epistemic configuration was used (Figure 2), which according to Font and Godino (2006), is made up of the set of situation-problems (extra-mathematical and intramathematical applications of the mathematical object), language (terms, expressions and graphic notations of the mathematical object in its various representation registers), procedures (techniques used in the resolution of a task), concepts (introduced through definitions or descriptions), propositions (statements about concepts used in the resolution of a task), and arguments (statements used to validate or explain the propositions and procedures) associated, in this case, with the natural number.

The epistemic analysis was oriented to characterise the emerging primary objects in the resolution of interactive activities (tasks on mobile devices) according to the following considerations: for the situationproblems, the meaning addressed in the task was identified (cardinal, numerical sequence, operational, symbolic, ordinal, or measure); in the case of language, the representations used (verbal, symbolic, manipulative material, or graphic) as well as the concepts promoted in 

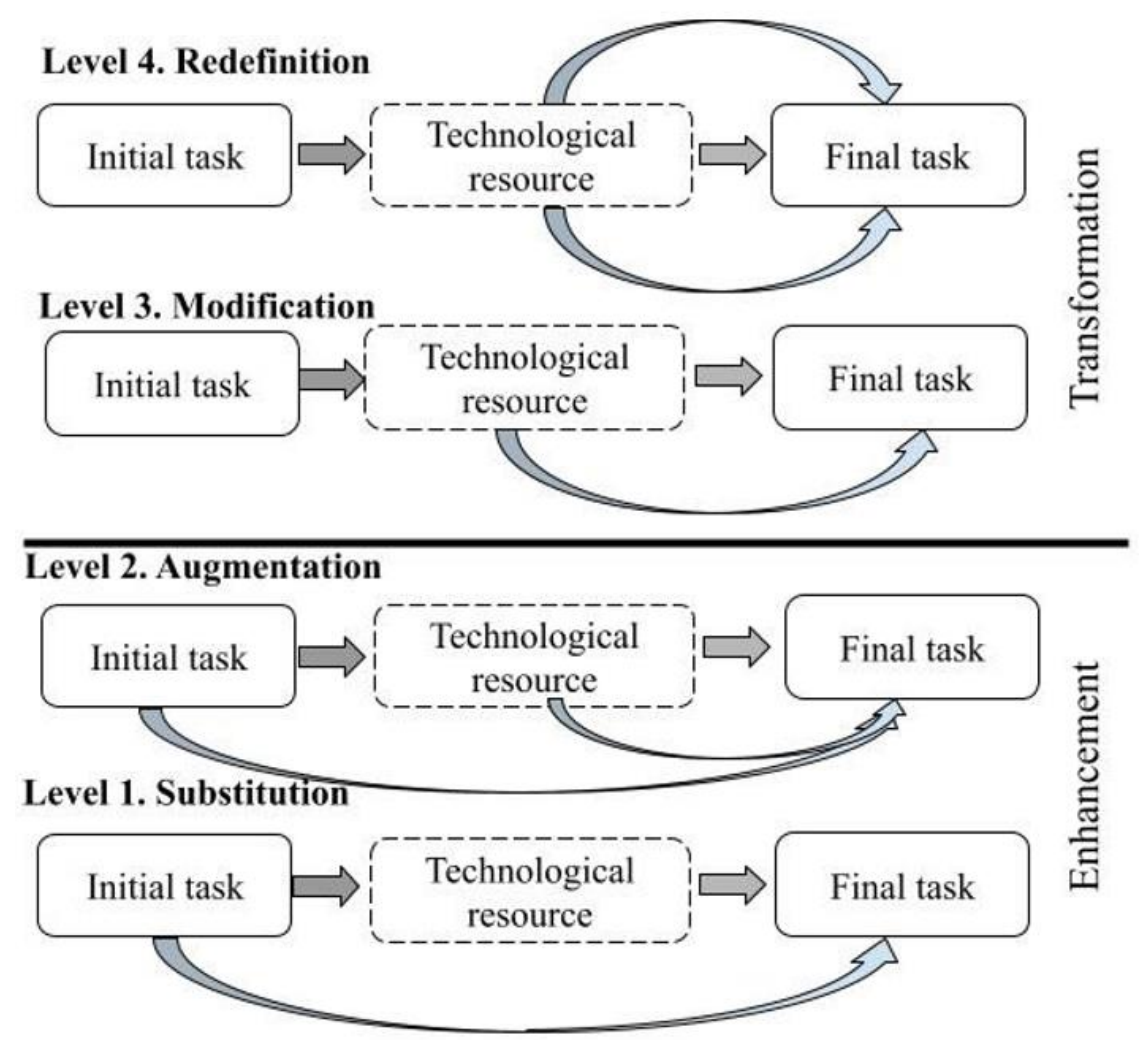

Figure 3. SAMR model levels

the tasks (for example, ordinal number, ten, or hundred). The procedure performed for the resolution of the tasks, the propositions established, and the arguments to validate procedures or propositions were identified.

\section{Mediational Suitability}

The mediational suitability is related to "the degree of availability and adequacy of material and temporal resources for the development of the teaching-learning process" (Godino, 2013, p. 124) and for its analysis there are components and indicators of suitability (Breda et al., 2018; Godino, 2013). According to the nature of the research, it focused on material resources as an element of assessment and established criteria of suitability to assess the technological resource used in the design of tasks.

To do this, the SAMR model (substitution, augmentation, modification, and redefinition) was used to guide the analysis and assessment of mediational suitability, since, according to the literature, its purpose is to help evaluate the way in which technologies are being incorporated into classrooms (Puentedura, 2014a, $2014 b$ ). To do this, a hierarchical set of four levels and two layers that describe the use of technological tools is proposed (Figure 3). The adaptation of the extended SAMR model (Crompton \& Burke, 2020) was carried out for the specific analysis of the tasks designed on mobile devices, subsequently, and given the objective of the research, the indicators of mediational suitability were adapted (Godino, 2013) for assessing the level of integration of the technology used in the design of tasks.
In Figure 3, the term initial task, referring to a task designed without the use of technology, and final task is a task that was designed using a technological resource. Below, we show what each level consists of:

- Substitution. It is the lowest level of the use of the technological resource in the design of tasks. Teachers design tasks that are a direct substitution for tasks that can normally be performed without digital technology.

- Augmentation. At this level, the designed task uses some tools of the technological resource and adds functional improvements, however, the effect on the learning outcomes of the students can be minimal or none.

- Modification. Technology enables meaningful task design. Teachers use the resource to create tasks that cannot be achieved without the use of digital technology, that is to say, at this level the task is designed from the technological resource.

- Redefinition. At this level, teachers design new tasks that without the use of technological resources would be impossible, in this case, the tasks do not bear a resemblance to the tasks that are normally proposed without the technological resource.

In Table 2, the indicators of mediational suitability based on what is reported in the literature and what is established in Godino (2013) are presented. 
Table 2. Indicators of mediational suitability

Component Indicators

Technological resource for The level at which the technological resource for the design of tasks is integrated is high.

the design of tasks on The technological resource allows teachers to introduce situation-problems, language, procedures,

mobile devices

conceptions, propositions, and arguments that adapt to the mathematical content taught.

(smartphone, laptop and The technological resource allows for the design of tasks according to the educational level to which tablet)

it is directed.

The technological resource is easy to use and allows for the design of tasks for mobile devices.

Table 3. Personal data of participants

\begin{tabular}{lccc}
\hline Participant & Age & Academic background & Teaching experience (years) \\
\hline Teacher $_{1}$ & 28 & Bachelor of Science in Mathematics & 4 \\
Teacher $_{2}$ & 28 & Bachelor's Degree in Primary Education & 3 \\
\hline
\end{tabular}

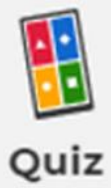

(a)

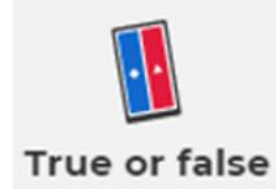

(b)

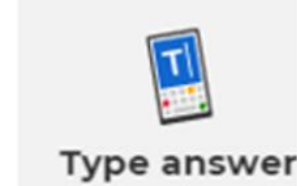

(c)

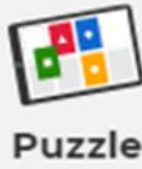

(d)

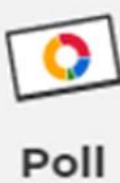

(e)

Figure 4. Types of tasks in Kahoot, (a) Quiz task, (b) True of false task, (c) Type the answer task, (d) Puzzle task, (e) Poll task

\section{METHODOLOGY}

The proposed indicators of epistemic and mediational suitability were used to evaluate tasks designed by two primary school teachers. To achieve the above, a qualitative methodology at the descriptive level was followed and the following phases were established in the research:

a. establish indicators of epistemic and mediational suitability (the proposed indicators of epistemic and mediational suitability are shown in the Theoretical Elements section);

b. data collection;

c. task analysis and assessment of epistemic suitability; and

d. task analysis and assessment of mediational suitability.

\section{Participants and Research Context}

Two primary school teachers participated in this study, selected using a non-probability sampling (Hernández et al., 2014) of intentional type (Otzen \& Manterola, 2017). These teachers had the following characteristics: 1) in-service third grade teachers and 2) availability to take the workshop and be trained in the design of tasks on Kahoot. In Table 3, their personal data are presented.

At the time of the investigation, the health emergency due to COVID-19 occurred worldwide. For this reason, the context where classes were taught was in a completely virtual way, in accordance with the indications of the Secretary of Public Education (SEP) in Mexico. Thus, teacher ${ }_{1}$ taught classes by video call, using
Zoom and mobile devices such as a laptop, a tablet, and a smartphone. On the other hand, teacher 2 used WhatsApp messaging and a smartphone as a means of communication.

\section{Data Collection}

\section{Technological resource}

In this research, Kahoot (https://kahoot.com/ schools-u/) was used. It is a technological resource that allows users to design interactive activities (tasks) that can be played on a smartphone, a tablet, and a laptop. This resource is interactive and intuitive and allows its users to design tasks for mobile devices without the need to have advanced knowledge in programming, the latter being the reason why it was selected.

In the premium version of this resource you can design the following tasks:

a. quiz (Figure 4a), in which a question is asked and the answer must be selected among four answer options;

b. true or false (Figure $4 \mathrm{~b}$ ), in this case, a question is asked and it is indicated if it is true or false;

c. type the answer (Figure 4c), users can type the answer from their devices;

d. puzzles (Figure 4d), in which an order between the four answer options can be indicated;

e. poll (Figure 4e), where one of the four options is selected as an answer.

\section{Teacher training}

For the design of tasks, teachers were trained with the implementation of the Design of Interactive Lessons in Kahoot Workshop. It was structured based on the phases 
Table 4. Organization of workshop sessions

\begin{tabular}{ll}
\hline Session & Purpose \\
\hline 1 & Knowledge about the features of Kahoot \\
3 & Knowledge about the reference meaning of the natural number \\
4 & Design of tasks in Kahoot \\
5 & \\
6 & Validation and implementation of tasks \\
\hline 8 & \\
\hline
\end{tabular}

Table 5. Tasks designed by teachers

\begin{tabular}{|c|c|c|c|}
\hline Participant & Meaning of the natural number & Lesson & Number of tasks \\
\hline \multirow[t]{6}{*}{ Teacher $_{1}$} & Number sequence & Four-digit number & 10 \\
\hline & & Order and sequence & 10 \\
\hline & Operational & Basic operations & 10 \\
\hline & & Mental calculation 1 & 10 \\
\hline & Ordinal & Ordinal numbers & 10 \\
\hline & Measure & Longitude & 10 \\
\hline \multirow[t]{6}{*}{ Teacher $_{2}$} & Number sequence & Which is greater? & 10 \\
\hline & & Number sequence & 10 \\
\hline & Operational & Basic operations & 10 \\
\hline & & Additive decomposition & 10 \\
\hline & Ordinal & Ordinal numbers & 10 \\
\hline & \multicolumn{2}{|l|}{ Total } & 110 \\
\hline
\end{tabular}

of didactic engineering proposed by OSA (Godino et al., 2014). The workshop was given for eight weeks (one session per week) in virtual mode using Google Meet as a means of communication. Each session was videotaped with an approximate duration of two hours. In addition, extra activities were scheduled on Google Classroom that complemented the virtual sessions. Table 4 presents the organization and purpose of each workshop session.

During sessions 1 and 2, basic aspects such as creating an account, characteristics about the type of tasks that can be designed, among other functions of Kahoot, were addressed. Also, in sessions 3 and 4, the reference meaning of the natural number was presented and discussed with the teachers. Subsequently, sessions 5 and 6, were dedicated to the design of tasks in Kahoot.

Finally, in sessions 7 and 8 the tasks designed were validated, firstly between the first author (researcher) and the teachers participating in the workshop, and secondly when they were implemented with the students.

With the workshop, the teachers designed a total of 110 tasks organized into lessons. Table 5 presents information on the meaning addressed, the title of the lesson, and the number of tasks included.

\section{Data Analysis}

The 110 tasks were analysed in two moments. In the first, primary objects were identified (situationproblems, language, procedures, concepts, proposals, and arguments) involved in each meaning of the natural number (numerical sequence, operational, ordinal, and measure) using the epistemic configuration (Font \& Godino, 2006; Morales-Garcia \& Díaz-Levicoy, 2022; Morales-Garcia et al., 2021)) to inform on the intended meaning of the mathematical object, and subsequently the indicators of epistemic suitability were applied to assess the tasks.

In the second moment, it was identified if the tasks corresponded to the levels of substitution, augmentation, modification, or redefinition (Crompton \& Burke, 2020) and in due course the indicators of mediational suitability were applied.

\section{RESULTS}

\section{Epistemic Suitability}

The teachers designed 40 tasks on number sequence, 40 on operational meaning, 20 on ordinal meaning, and 10 for the meaning of measure. Next, some examples of the analysis of the tasks associated with each meaning of the natural number, the primary objects identified organised in epistemic configurations (Font \& Godino, 2006) and the assessment of the epistemic suitability are presented. We clarify that the examples were selected from the product of each teacher and keeping in mind that these made evident the related practices with the approached meaning.

\section{Meaning of number sequence}

The situation-problems included were intramathematical, focused on the comparison of numbers of three (teacher 1 ) and four (teacher 2 ) digits. Figure 5 presents an example of the tasks included and their 


\section{Select the image that has the lesser number.}

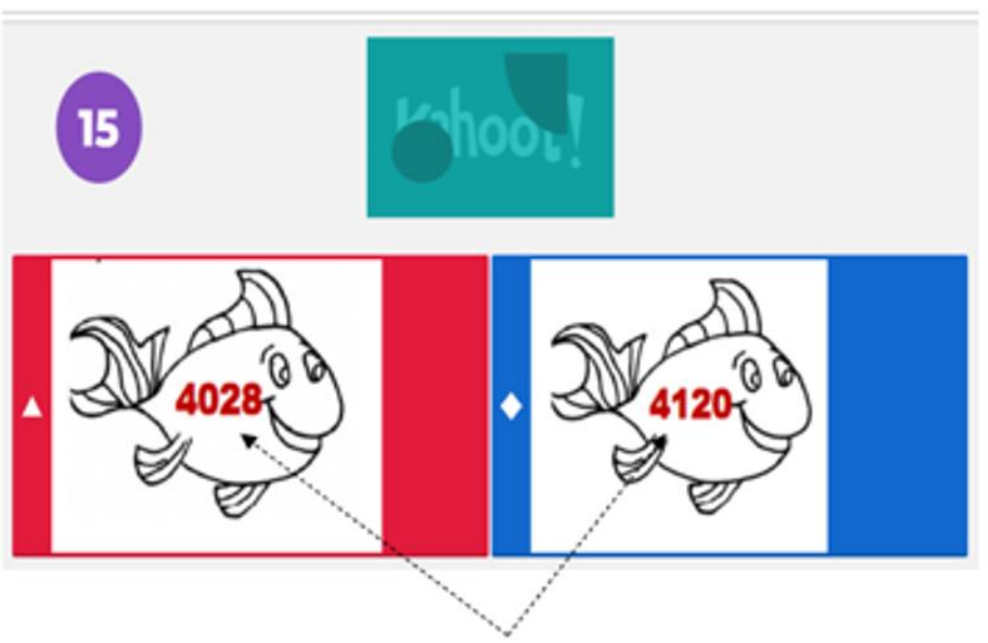

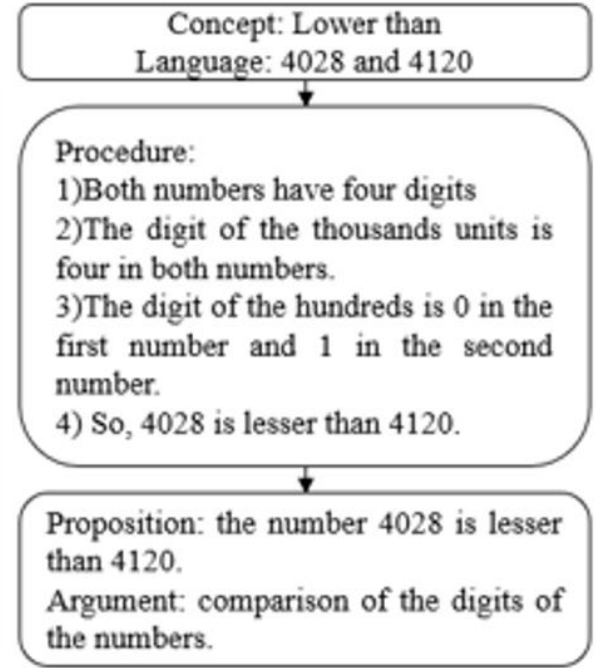

Argument: comparison of the digits of

Symbolic representation

(a) Analysis of Teacher ${ }_{1}^{\prime}$ s task
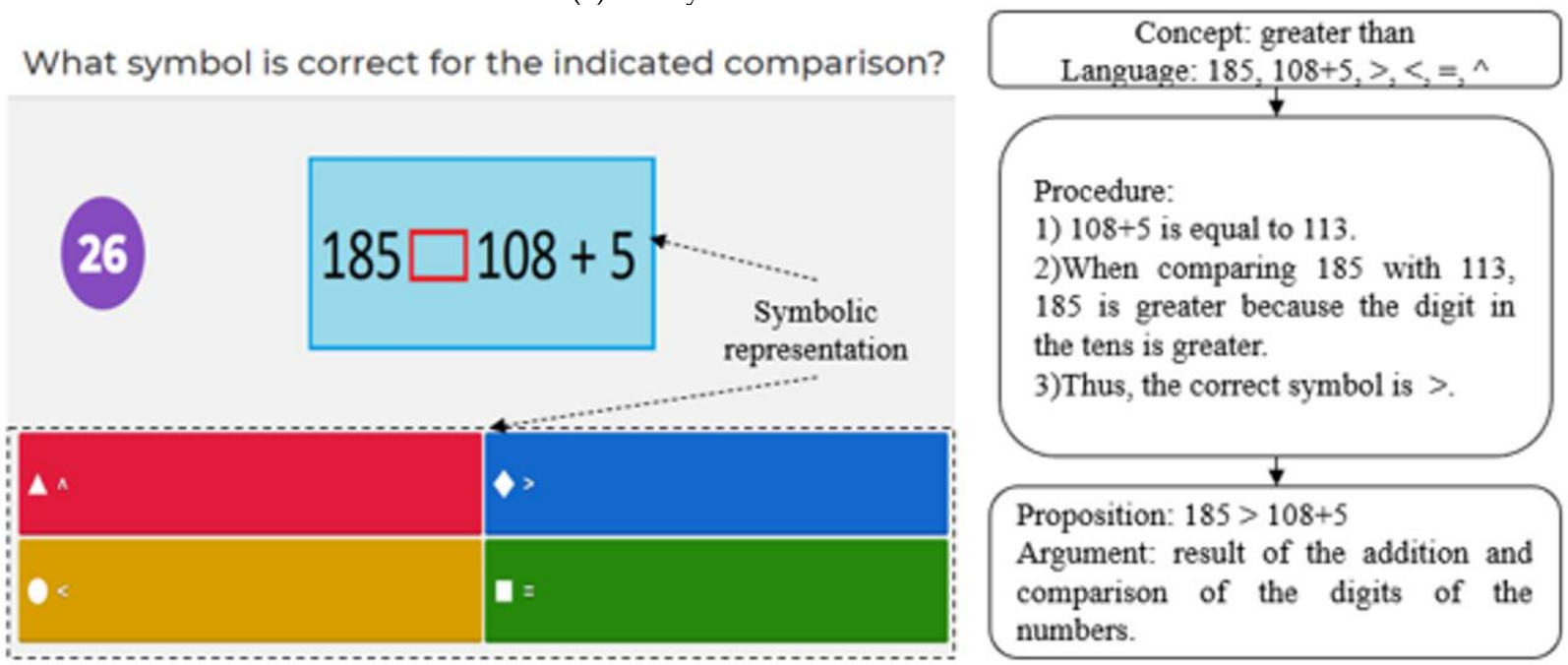

(b) Analysis of Teacher's's task

Figure 5. Meaning of number sequence

Table 6. Epistemic configuration of number sequence meaning

\begin{tabular}{|c|c|}
\hline Primary objects & Description \\
\hline Situation-problems & -Situation-problems involving the comparison of three- and four-digit numbers. \\
\hline \multirow[t]{3}{*}{ Language } & -Symbolic representation of three- and four-digit numbers. \\
\hline & -Symbolic expression of the sum, for example, “108+5" (Figure 5b). \\
\hline & -Use of the symbols " $<,>$ or $="$ to indicate the order relationship between two numbers (Figure $5 b$ ). \\
\hline Procedures & $\begin{array}{l}\text {-The procedure was oriented to the comparison of the digits of a number, to indicate when a number is } \\
\text { greater than, lesser than or equal to another; see for example the procedures indicated in Figure } 5 \text {. }\end{array}$ \\
\hline & Sometimes, before performing this procedure, you must solve sum operations (Figure $5 b$ ). \\
\hline Concepts & -Number sequence, lesser than $(<)$, greater than $(>)$ or equal to $(=)$. \\
\hline Propositions & $\begin{array}{l}\text {-They are related to the result of the comparison of the numbers, for example, " } 4028 \text { is less than } 4120 \text { " } \\
\text { (Figure } 5 \mathrm{a} \text { ) or " } 185>108+5 \text { " (Figure } 5 \mathrm{~b} \text { ). }\end{array}$ \\
\hline Arguments & - Knowledge about the order relationship in the number sequence. \\
\hline
\end{tabular}

analysis. The primary objects identified in this meaning were organised in Table 6.

\section{Operational meaning}

In this meaning, the teachers designed intramathematical tasks focused on the calculation of addition, subtraction, multiplication, and division operations. Below is an example of the type of tasks included and their analysis (Figure 6), as well as the primary objects identified (Table 7). 

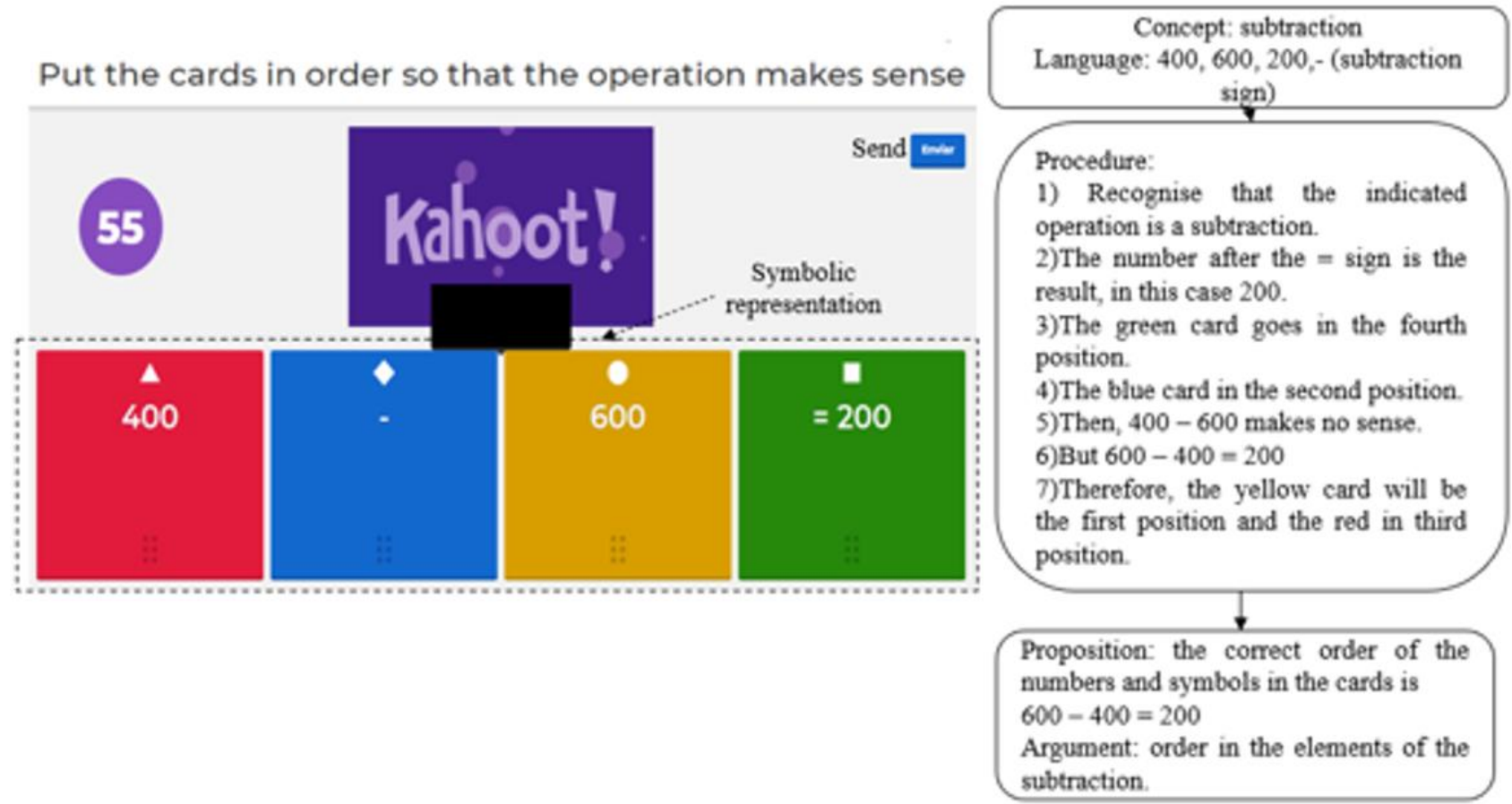

(a) Analysis of Teacher ${ }_{1}$ 's task

\section{What is the result of adding 370 and $210 ?$}
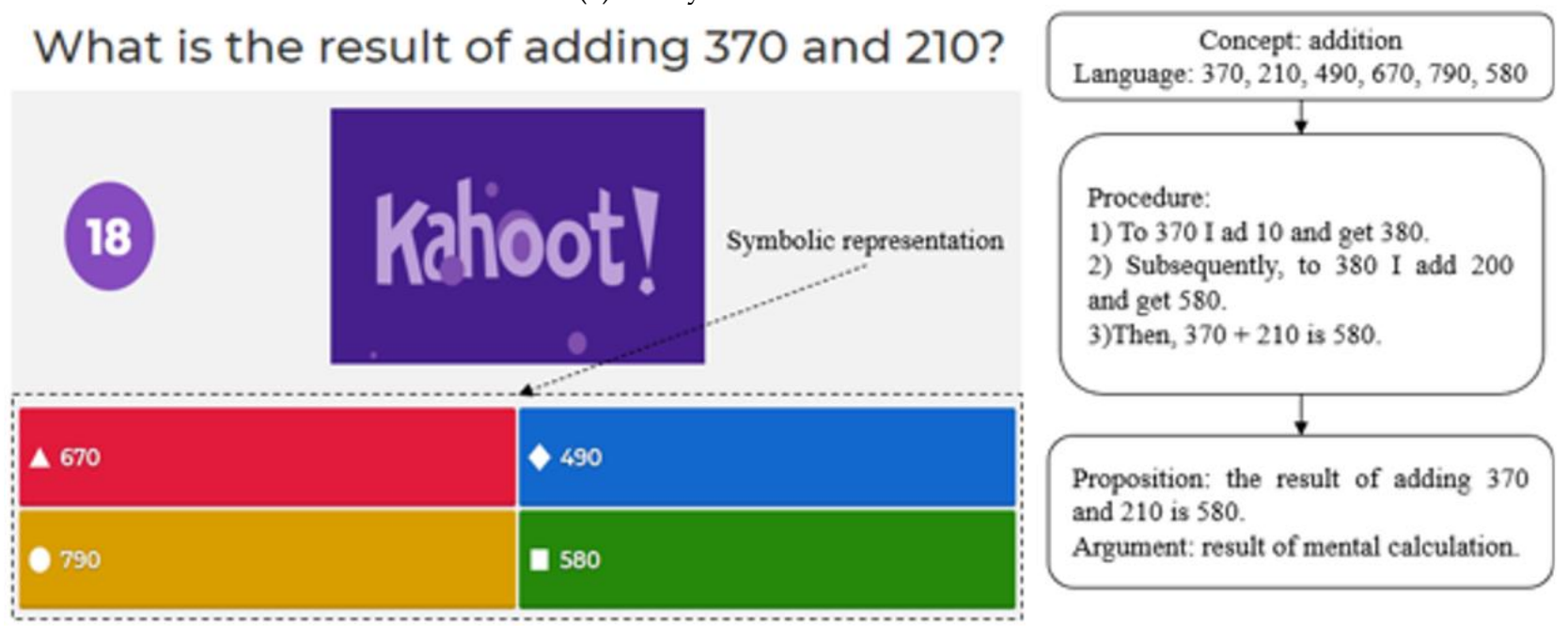

Figure 6. Operational meaning

(b) Analysis of Teacher's's task

Table 7. Epistemic configuration of operational meaning

\begin{tabular}{|c|c|}
\hline Primary objects & Description \\
\hline Situation-problems & $\begin{array}{l}\text {-Situation-problems to perform a mental calculation of basic operations. As well as to recognise the order } \\
\text { in the elements of addition, subtraction, or division. }\end{array}$ \\
\hline Language & $\begin{array}{l}\text {-Symbolic representation of three-digit numbers. } \\
\text {-Symbolic and/or verbal representation of the operations of addition }(+) \text {, subtraction }(-), \text { multiplication } \\
(\times) \text {, and division }(\div) \text {. }\end{array}$ \\
\hline Procedures & $\begin{array}{l}\text {-The tasks were designed to perform mental calculation, that is to say, you cannot use pencil, paper, or a } \\
\text { calculator to solve the operations, instead you use procedures that could be performed mentally, such as } \\
\text { adding hundreds with hundreds, tens with tens or completing the tens. For example, by adding } 370 \text { and } \\
210 \text {, they could perform this procedure to " } 370 \text { I add 10, and I would have } 380 \text {, then } 380 \text { plus } 200 \text { is } 580 \text {, } \\
\text { then the result is } 580 \text { " (Figure 6b). }\end{array}$ \\
\hline Concepts & -Addition, subtraction, multiplication, and division. \\
\hline Propositions & $\begin{array}{l}\text { - Result of the operation performed, for example, "the result of adding } 370 \text { and } 210 \text { is } 580 \text { " (Figure 6b) or } \\
\text { "the correct order of the elements of a subtraction is } 600-400=200 \text { " (Figure 6a). }\end{array}$ \\
\hline Arguments & -Correct procedure when adding, subtracting, multiplying, or dividing mentally. \\
\hline
\end{tabular}




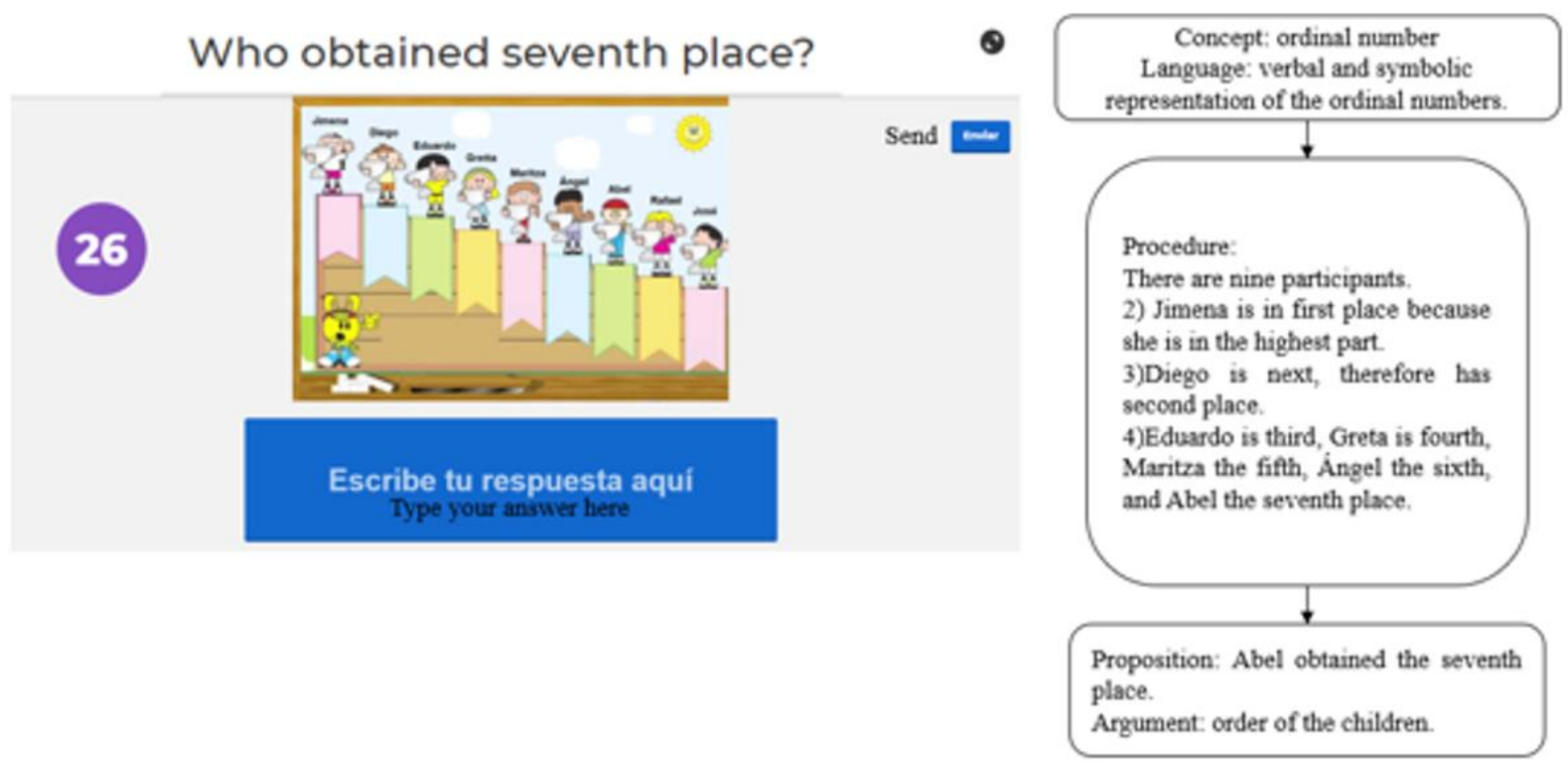

(a) Analysis of Teacher ${ }_{1}^{\prime}$ s task
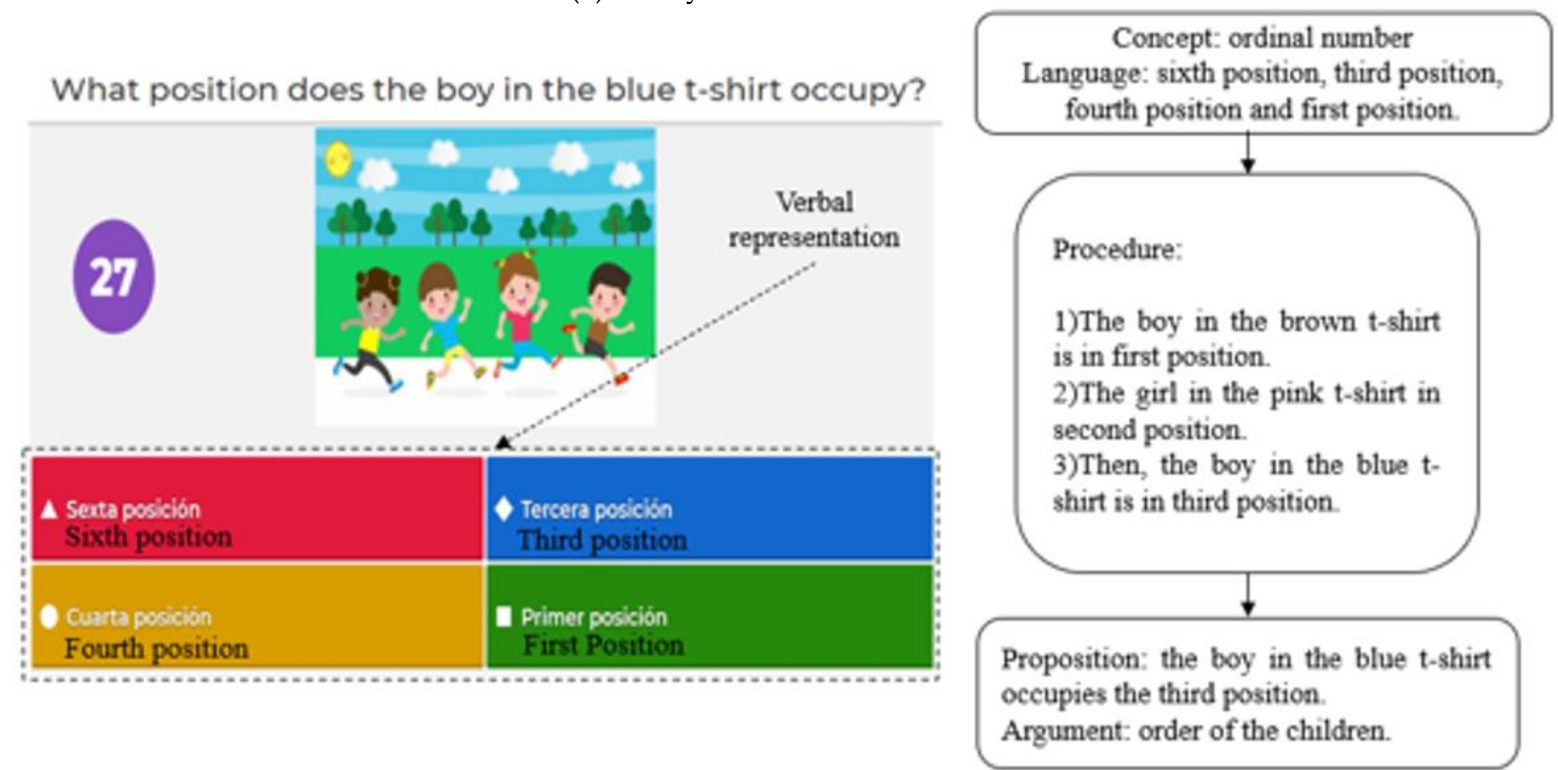

Figure 7. Ordinal meaning

(b) Analysis of Teacher's's task

Table 8. Epistemic configuration of ordinal meaning

\begin{tabular}{|c|c|}
\hline Primary objects & Description \\
\hline Situation-problems & $\begin{array}{l}\text {-Situation-problems on the ordinal meaning focused on the application of the ordinal number in } \\
\text { context situations, for example, a children's race (Figure 7) or the identification of floors in a building (first } \\
\text { floor, second floor, or third floor). } \\
\text {-Situation-problems to sort ordinal numbers. }\end{array}$ \\
\hline Language & $\begin{array}{l}\text {-Verbal representation (first, second, third, fourth, fifth, sixth, seventh, eighth, ninth, and tenth). } \\
\left.\text {-Symbolic representation ( } 1^{\mathrm{st}}, 2^{\text {nd }}, 3^{\text {rd }}, 4^{\text {th }}, 5^{\text {th }}, 6^{\text {th }}, 7^{\text {th }}, 8^{\text {th }}, 9^{\text {th }} \text {, and } 10^{\text {th }}\right) .\end{array}$ \\
\hline Procedures & $\begin{array}{l}\text {-Determine the object that is situated in the first position and then locate the remaining places, for } \\
\text { example, the procedure proposed in Figure } 7 \mathrm{a} \text { and Figure } 7 \mathrm{~b} \text {. }\end{array}$ \\
\hline Concepts & -Ordinal number. \\
\hline Propositions & $\begin{array}{l}\text {-Focused on identifying the place occupied by each participant or object, for example, "Abel obtained } \\
\text { seventh place" (Figure } 7 \mathrm{~b} \text { ). }\end{array}$ \\
\hline Arguments & owledge of ordinal numbers and their use to indicate the order in a set of objects. \\
\hline
\end{tabular}

\section{Ordinal meaning}

In this meaning, teachers designed extramathematical and intra-mathematical tasks focused on the use of the ordinal number in different contexts. Below is an example of the designed tasks and their analysis (Figure 7) as well as the epistemic configuration of primary objects (Table 8). 
Select the smallest sized object

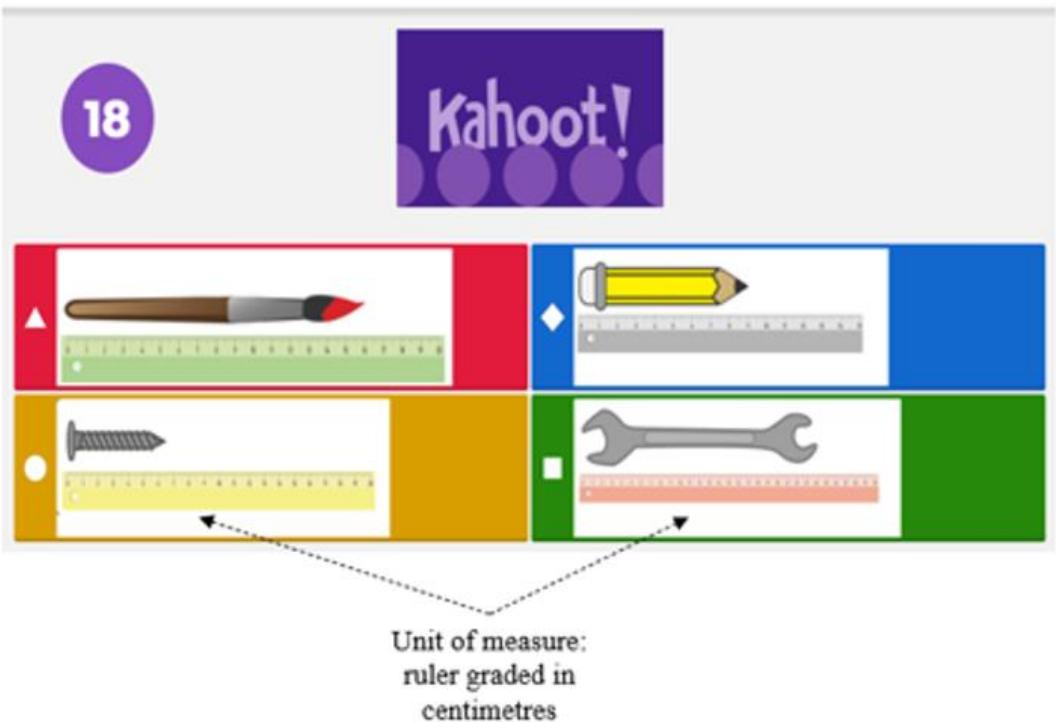

(a) Analysis of Teacher ${ }_{1}^{\prime}$ s task

Maria is the tallest of the three. How tall is Maria?

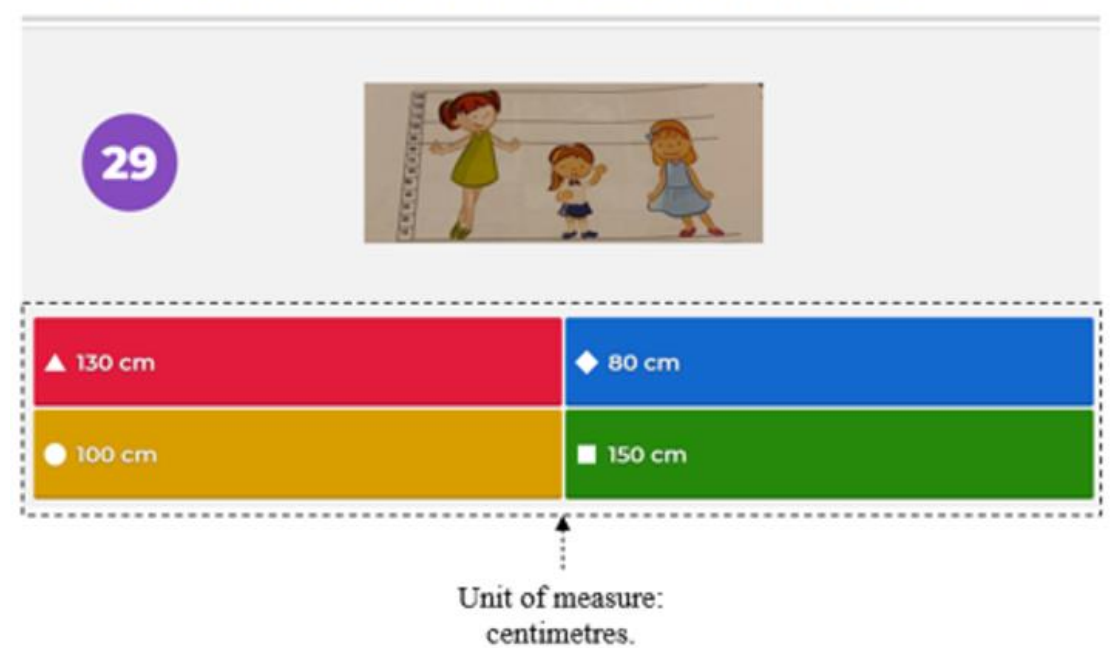

Concept: length, estimation Language: $1 \mathrm{~cm}, 2 \mathrm{~cm}, 3 \mathrm{~cm} \ldots 30 \mathrm{~cm}$

Procedure:

The paintbrush measures $16 \mathrm{~cm}$ approximately

2)The pencil measures $9.5 \mathrm{~cm}$ approximately.

3)The screw measures $6.5 \mathrm{~cm}$ approximately.

4) The wrench $24 \mathrm{~cm}$.

5)Therefore, the screw is the one with the shortest length.

Proposition: the object with the shortest length is the screw.

Argument: length of the objects.

\section{Concept: length, height}

Language: $130 \mathrm{~cm}, 80 \mathrm{~cm}, 100 \mathrm{~cm}$, and $150 \mathrm{~cm}$.

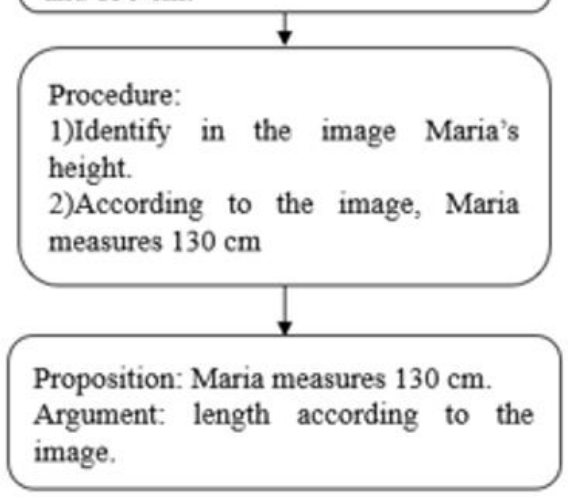

Figure 8. Meaning of measure

(b) Analysis of Teacher ${ }_{1}^{\prime}$ s task

Table 9. Epistemic configuration of the meaning of measure

\begin{tabular}{|c|c|}
\hline Primary objects & Description \\
\hline Situation-problems & $\begin{array}{l}\text {-Situation-problems involve situations to determine a child's height (Figure 8b), calculate and/or estimate } \\
\text { the length of a brush or paintbrush (Figure 8a), and order lengths. }\end{array}$ \\
\hline Language & $\begin{array}{l}\text {-Verbal and symbolic representation of three-digit numbers. } \\
\text {-Symbolic representation of the units of measurement (centimetres). }\end{array}$ \\
\hline Procedures & $\begin{array}{l}\text {-Use of a graded ruler in centimetres (Figure } 8 \mathrm{a} \text { ). } \\
\text {-Visual estimation, to determine which object is larger or smaller. } \\
\text {-Use of a height scale, based on centimetres (Figure } 8 \mathrm{~b} \text { ). }\end{array}$ \\
\hline Concepts & -Length, estimation, and unit of measurement. \\
\hline Propositions & $\begin{array}{l}\text {-Focused on determining the length of objects or people, for example, "the smallest object is the screw" } \\
\text { (Figure 8a) or "Maria measures } 130 \mathrm{~cm}^{\prime} \text { (Figure 8b). }\end{array}$ \\
\hline Arguments & -Calculation or correct estimation of the length of objects or people. \\
\hline
\end{tabular}

\section{Meaning of measure}

In the case of the meaning of measure, the tasks are of an extra-mathematical type and were focused on determining the length of different objects (pencil, nail, paintbrush, among others) and the height of children, using graduated instruments or using estimation. Below is an example of the designed tasks and their analysis (Figure 8) as well as the associated epistemic configuration (Table 9). 


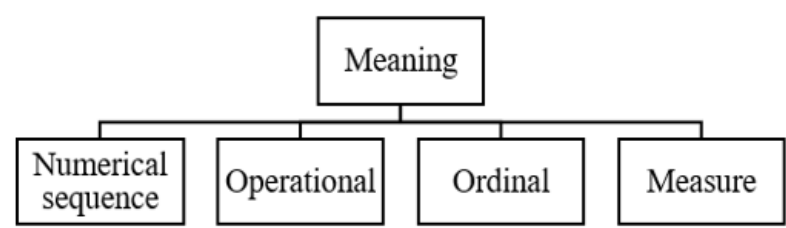

Figure 9. Meanings addressed in the tasks

\section{Assessment of the epistemic suitability of tasks}

The assessment of suitability was achieved by contrasting the reference meaning and the intended meaning of the natural number. In the case of the situation-problems component, it is taken as an indicator that situation-problems are presented that promote the use of the natural number as a numerical sequence, cardinal, ordinal, operational, symbolic, and measure; in this case, the tasks included four of the six meanings established in the reference meaning (Figure 9).

The foregoing due to the fact that the teachers were dealing with these contents in the third grade of primary education at the time of the development of the workshop. The importance of designing tasks from the meaning of the natural number lies in the fact that it is considered an important component in the development of number sense.

For the language component, the indicator is that the use of different representations of the natural number (verbal, symbolic, manipulative material, and graphic) is promoted; with the analysis of the 110 tasks, it is evidenced that the representations prioritised by the teachers are the symbolic and verbal representations in the different meanings of the natural number. Teachers do not incorporate in their designs, virtual manipulative material or graphic representation of the natural number (point configurations, number line, or numerical tables) this being an aspect that should be promoted in upcoming research. The above would allow for the design of tasks rich in mathematical content.

On the rules component, it is taken as an indicator that it includes concepts, propositions, and procedures appropriate to the school level to which they are directed; with the analysis of the tasks, it is evident that the concepts (greater than, lesser than, addition, subtraction, ordinal number, among others), propositions (185>108 +5 , Maria measures $130 \mathrm{~cm}$, the child in a blue t-shirt occupies the third position, and among others) and the procedures (comparison of numbers, estimation, mental calculation, etc.) included in the resolution of the tasks are appropriate for the school level to which they are directed. On the other hand, for the arguments component, it is taken as an indicator that situations in which it must be argued are promoted about this indicator; the resource includes activities of true or false, which promotes reflection and therefore the argumentation on the truth or falsity of the questions asked, and the puzzle activities also allow students to reflect and question how to indicate an order to the answers given, for example to organise numbers in numeric sequences or lengths.

Finally, in the case of the relations component, it was established as an indicator that it presents situations to transit between the different representations of the natural number (symbolic, verbal, manipulative material, and graphic). The proposed situations promote the transit between the verbal and symbolic representation of the natural numbers in the different meanings addressed. However, it is considered necessary to include representations of manipulative material and graphics of natural numbers, since it would increase the number of relationships that can be established, and the foregoing is an important element to improve the understanding of this concept.

\section{Mediational Suitability}

To assess the mediational suitability, they used the levels of analysis of the extended SAMR model, with the purpose of identifying the level of integration of mobile technology in the design of tasks for the concept of natural number in a completely virtual context. Overall, we included 47 quiz tasks, 23 true or false, 25 type the answer, 10 puzzle and 5 poll-type, which make a total of 110 tasks. Figure 10 then shows a graph indicating the level at which the tasks designed by the teachers are located.

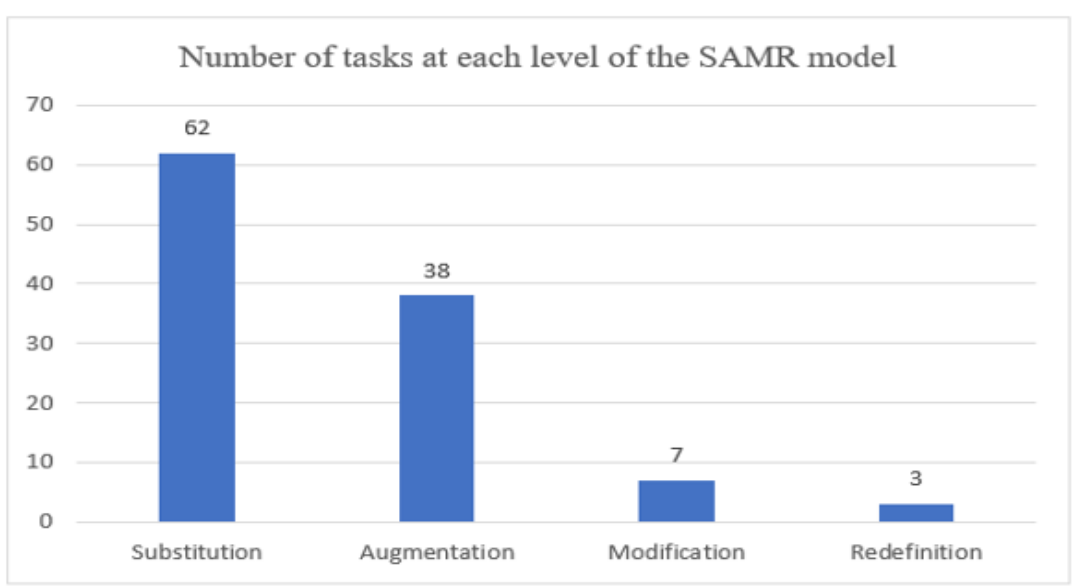

Figure 10. Level of integration of the technological resource in the design of tasks according to the SAMR model 
Match each number with its additive decomposition

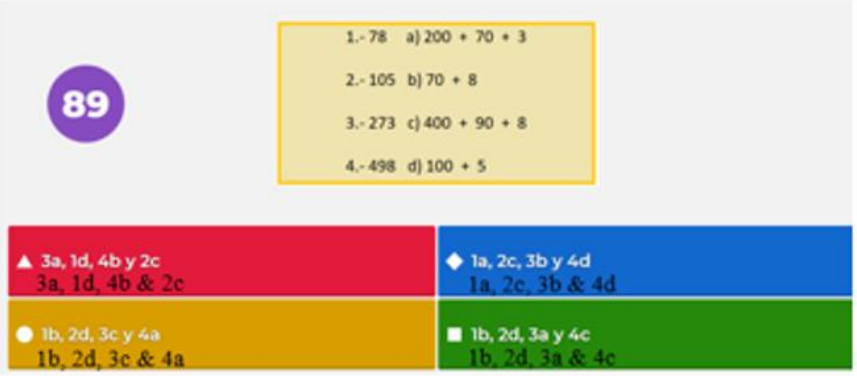

(a) Teacher ${ }_{1}^{\prime}$ s task

Figure 11. Substitution level

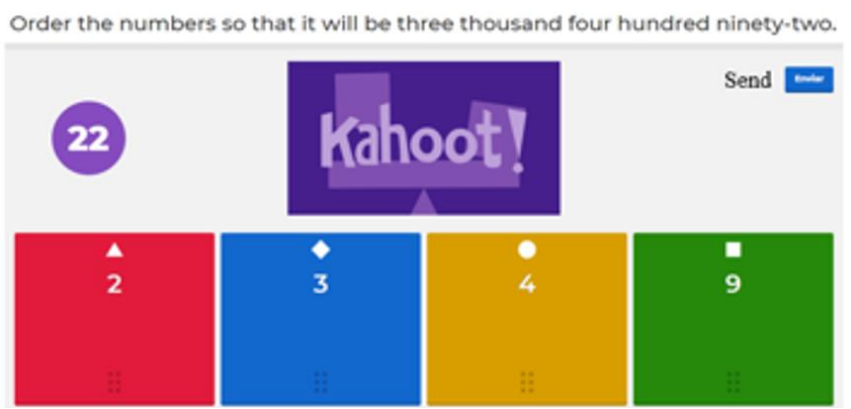

(a) Teacher ${ }_{1}^{\prime}$ s task

Figure 12. Level of augmentation

Order the cards in such a way that the operation makes sens

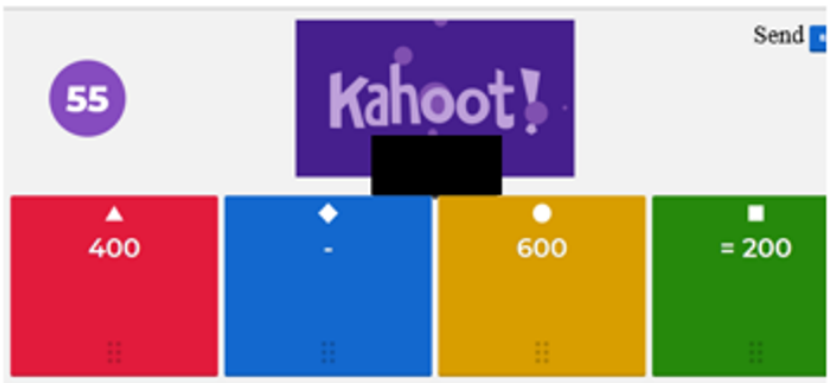

(a) Teacher ${ }_{1}^{\prime}$ s task

Figure 13. Modification level

\section{Substitution}

In this case, interactive activities are only used as a direct substitute for the tasks that teachers normally design, without the use of digital technology. In Figure 11, two tasks are shown that are included in this level, for example, in Figure 11a, it is asked to relate the numbers 78, 105, 273, and 498 with their additive decomposition, while in Figure $11 \mathrm{~b}$ it is asked to calculate the result of the sums indicated. In both cases, and in general, the 62 tasks included in this level used Kahoot as a means that directly replaces the tasks that teachers normally propose without the use of the technological resource.

\section{Augmentation}

At this level, the tasks designed use some Kahoot tools, which add functional improvements to the task.
What are the results of the indicated sums?

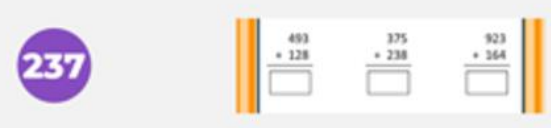

\begin{tabular}{|c|c|}
\hline$\Delta 621,624$ y 1083 & $<613,450$ y 210 \\
\hline - 621, cos y 1007 & D. 350,675 y 1036 \\
\hline
\end{tabular}

(b) Teacher ${ }_{2}^{\prime}$ s task

Order from lowest to highest the following ordinal numbers.

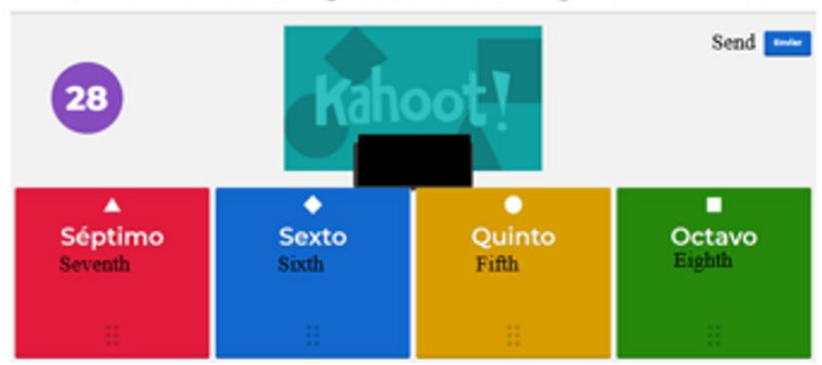

(b) Teacher2's task
Order the cards in such a way that the operation is corre
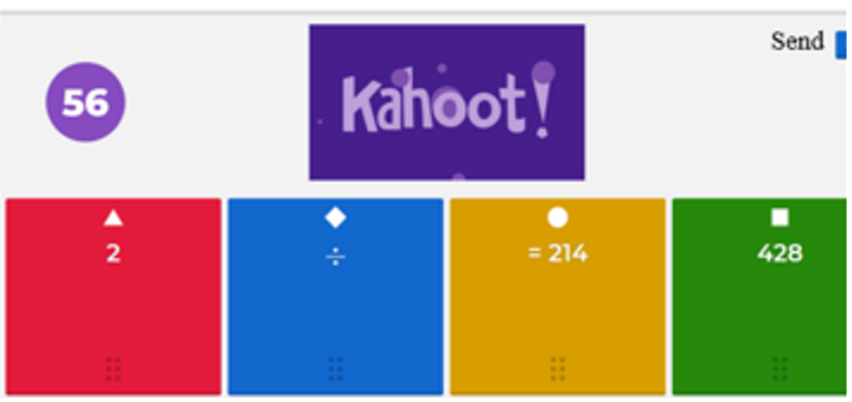

(b) Analysis of Teacher ${ }_{1}^{\prime}$ s task

For example, in Figure 12a, an interactive puzzle-type activity is used, which allows to order the numbers presented in the coloured boxes, to symbolically represent the number three thousand four hundred ninetytwo. In this case, although the task can be performed without the use of technology, the possibility of dragging the numbers in the boxes adds a functional improvement to the task, as it allows you to interact with the answer. The same goes for the task in Figure 12b.

\section{Modification}

Teachers used Kahoot to create tasks that cannot be achieved without the use of digital technology, that is to say that at this level the task is designed using the technological resource. In Figure 13, teachers use a puzzle-type activity to assign an order to the coloured tiles, so that the subtraction operation (Figure 13a) or division (Figure 13b) makes sense. In general, these 


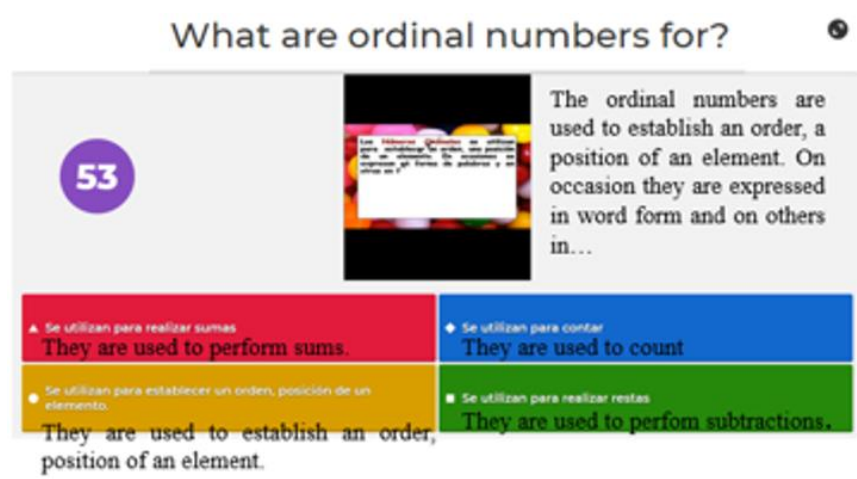

(a) Teacher's's task

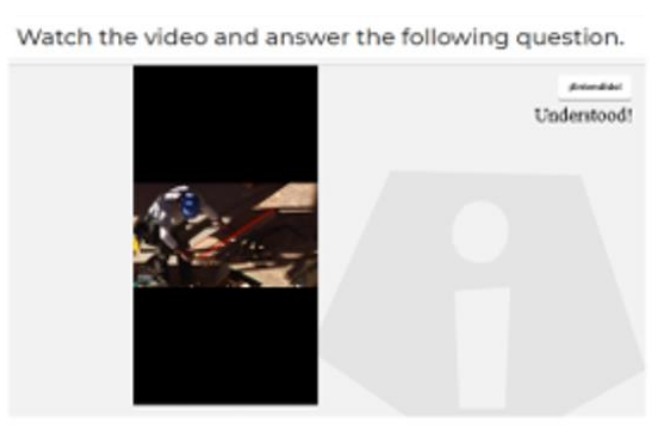

(b) Teacher1's task

Figure 14. Level of redefinition

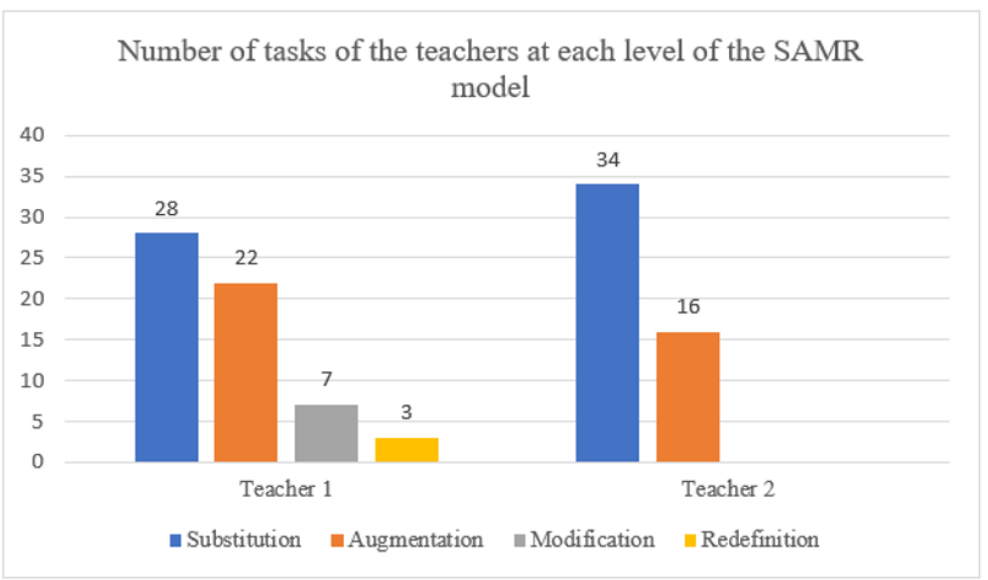

Figure 15. Level of the SAMR model in each teacher

types of tasks were designed using the technological resource and offer an option of interaction with the order of the elements of subtraction or division.

\section{Redefinition}

At this level, teachers design new tasks that without the use of technological resources would be impossible. For example, in Figure 14a, the teacher adds a video obtained from YouTube, which must be played to answer the question: What are ordinal numbers for? Or in Figure 14b, to answer the question: What is length? In both cases, teachers are proposing tasks that allow them to transform the way they teach.

\section{Assessment of mediational suitability}

The first indicator is that -the level at which the technological resource for the design of tasks is integrated is high; in Figure 15, information is presented on the number of tasks included in each level of the SAMR model. In the graph, it can be seen that for the most part, both teachers have designed tasks that are located at the substitution level, this being the lowest level of the integration of technology in the school context. Now, another aspect to highlight is that teacher ${ }_{1}$ designed tasks corresponding to the four levels of the SAMR model, while teacher 2 only designed tasks at the augmentation level.
Regarding the type of activities promoted by Kahoot, it was observed that the quiz tasks, true or false, type the answer and poll remained at a level of substitution or augmentation. Whereas the puzzle and exam tasks allowed Teacher ${ }_{1}$ to move to more advanced levels, such as modification and redefinition. It is remarkable that 62 of the 110 tasks, that is, $56 \%$ remained at a substitution level, so we consider that it is necessary to strengthen skills and competencies in teachers to move to the highest levels of the SAMR model based on the research.

As a second indicator, it is assessed whether -the technological resource allows teachers to introduce situations - problem, language, procedures, concepts, propositions, and arguments that adapt to the mathematical content taught. On this aspect, it is remarkable how Kahoot allowed for the introduction of different situation-problems, for example, mental calculation, estimation of lengths, indicate the finishing position in a race, among others, that allowed to address the different meanings of the natural number. Although in the tasks only symbolic and verbal language was used, the resource also allows the introduction of positional value tables, numerical tables, punctual configurations, through images or in YouTube videos, and these aspects should be promoted in future implementations. Finally, the concepts, propositions, and arguments identified in the tasks are related with the mathematical content. 
In the third indicator, it was assessed whether - the technological resource allows to design tasks according to the educational level to which it is directed. In this case, the tasks were aimed at students of the third grade of Primary Education, and without a doubt, the interactive activities that Kahoot has are in accordance with this school grade. An advantage is that teachers can easily adapt them to the needs of their group. Finally, on the fourth indicator - the technological resource is easy to use and allows for the design of tasks for mobile devices, the selected resource is definitely intuitive and easy to use since it has tools that allow teachers to quickly adapt to the activities and the design of tasks with them.

\section{DISCUSSION}

The research on mobile learning in Mathematics Education has shown the capacity to enhance motivation, learning, and teaching (Borba et al., 2016; Kyriakides et al., 2015). Nonetheless, research on the uses and potentialities that can be used as a basis for the implementation of devices is limited, which is why it is recommended to encourage the design of mobile content for the real integration of mobile technology with educational purposes (Brazuelo \& Gallego, 2014).

Furthermore, due to the health-emergency situation because of COVID-19, teachers are required to acquire skills for the management of different technological tools, and for this it is important to promote research on the design and assessment of mobile content. In that sense, this research uses the didactic suitability construct of the OSA and the SAMR model to tackle the problem related to the design and assessment of mobile content developed by the teachers themselves on a specific mathematical concept (Borba et al., 2016; Brazuelo \& Gallego, 2014; Kyriakides et al., 2015; Sung et al., 2016). For this reason, this research aimed to propose indicators of epistemic and mediational suitability to assess the mathematical content on natural numbers, and the level of integration of a technological resource in the design of tasks for mobile learning.

Regarding the assessment of epistemic suitability, indicators were proposed and implemented, and the mathematical objects involved in the resolution of tasks were analysed through the epistemic configuration (Font \& Godino, 2006). The importance of analysing the tasks from the position of epistemic suitability lies in the fact that the criterion of representativeness allows for the assessment of the mathematical quality of the instruction and can be considered when planning mathematical activities, since the choice of mathematical tasks that put into play the objects and mathematical meanings, in this case of the natural number, is crucial to promote significant learning (Pino-Fan et al., 2013).

In particular, the criterion of representativeness was used to contribute to research on uses and potentialities that could be the basis for the implementation of mobile devices in Mathematics Education (Borba et al., 2016; Kyriakides et al., 2015). In this sense, this research provides indicators of epistemic suitability for the design of mobile content and for the analysis of their mathematical content (Brazuelo \& Gallego, 2014; Sung et al., 2016) for the meaning of natural number in Primary Education. The assessment of the epistemic suitability of the tasks and the analysis of the representativeness of the reference meaning is an important criterion to determine the epistemological relevance of new curricular proposals (Pino-Fan et al., 2019), in this case, the proposals that are made from mobile learning.

On the other hand, analysing the tasks designed from the mediational suitability and the proposed indicators (Godino, 2013) allowed to identify the level of integration of the technological resource used in the design of tasks. Showing another perspective of the design of tasks for mobile learning, given that the real integration of these technologies in mathematics education does not consist in the simple use of mobile devices to show mathematical content, but that the tasks designed can be integrated into the characteristics of the resource used and to those of the mathematical concept studied.

In that sense, the use of the extended SAMR model (Crompton \& Burke, 2020) proved to be a useful tool in the assessment of tasks. The results indicate that $56 \%$ of the tasks remain at the level of substitution and this is related to what was pointed out by Crompton and Burke (2020) who stated that $46 \%$ of the time mobile devices are used to replicate activities that can be carried out without technology. In that sense, the results of this research allow to guide future research with teachers, since it informs some important aspects, for example, to encourage the design of tasks at the levels of modification and redefinition. In addition, Kahoot proved to be an intuitive and user-friendly resource that allows for the design of mobile content by the teachers themselves.

Another important aspect to highlight is the potential of epistemic and mediational suitability as elements to assess and guide the design of mobile content by the teachers themselves. Although this research addressed epistemic and mediational suitability, it is also important to address cognitive, affective, interactional, and ecological suitability, since these remain in the background when the instruction process is done using digital tools (Font \& Salas, 2020); for this reason, research on these aspects based on mobile learning is open.

\section{CONCLUSIONS}

Mobile learning is a new way for the introduction of digital technology into the mathematics classroom. In mathematics education, it is a topic that in countries like Mexico has been little explored, perhaps because of the refusal of teachers to use mobile devices in the class or 
because of the lack of preparation of teachers for the management and adaptation of mathematical content. However, now due to issues because of the COVID-19 pandemic, devices such as the smartphone, tablets, and laptops are the only means by which teachers are able to teach classes, and unfortunately, it is in this context where you can see the potential that this type of technology has in the instruction process.

But this potentiality not only lies in seeing mobile devices merely as resources that serve as a means to perform what was normally done without technology, but also to investigate how to use and adapt these resources to specific content, such as in this case the meanings of the natural number. In this sense, the established indicators of epistemic and mediational suitability allowed to publicise how the addressed mathematical content and the level of integration of the technological resource can be complemented in the design of tasks for a specific mathematical content. According to the research, it was found that the mathematical content of the tasks can be complemented by including other representations of the natural number. In addition, it is undoubtedly necessary to encourage the design of tasks that are positioned at the levels of modification and redefinition.

Author contributions: All authors have sufficiently contributed to the study, and agreed with the results and conclusions.

Funding: No funding source is reported for this study.

Declaration of interest: No conflict of interest is declared by authors.

\section{REFERENCES}

Aguilar, M. S., \& Puga, D. E. (2015). Mobile help seeking in mathematics: An exploratory study with Mexican engineering students. In H. Crompton, \& J. Traxler (Eds.), Mobile learning and mathematics. foundations, design, and case studies (pp.176-186). Routledge.

Alcalde Esteban, M., Pérez Serrano, I., \& Lorenzo, G. (2014). Los números naturales en el aula de primaria [Natural numbers in the primary school classroom]. Universidad Jaume I. https://doi.org/10.6035/ Sapientia90

Bano, M., Zowghi, D., Kearney, M., Schuck, S., \& Aubusson, P. (2018). Mobile learning for science and mathematics school education: A systematic review of empirical evidence. Computers $\mathcal{E}$ Education, 121, 30-58. https://doi.org/0.1016/ j.compedu.2018.02.006

Beltrán-Pellicer, P., Giacomone, B., \& Burgos, M. (2018). Online educational videos according to specific didactics: The case of mathematics. Cultura $y$ Educación, 30(4), 633-662. https:/ / doi.org/10.1080/ 11356405.2018.1524651

Beltrán-Pellicer, P., Medina, A., \& Quero, M. (2018). Movies and TV series fragments in mathematics: epistemic suitability of instructional designs. International Journal of Innovation in Science and Mathematics Education, 26(1), 16-26.

Benali, M., \& Ally, M. (2020). Towards a conceptual framework highlighting mobile learning challenges. International Journal of Mobile and Blended Learning, 12(1), 51-63. https://doi.org/10. 1111/jcal.12505

Borba, M. C., Askar, P., Engelbrech, J., Gadanidis, G., Linares, S., \& Sánchez, M. (2016). Blended learning, e-learning and mobile learning in mathematics education. ZDM Mathematics Education, 48(5), 589610. https:/ / doi.org/10.1007/s11858-016-0798-4

Brazuelo, F., \& Gallego, D. J. (2014). Estado del mobile learning en España [The state of mobile learning in Spain]. Educar em Revista [Educate in Magazine], 4, 99-128. https:/ / doi.org/10.1590/0104-4060.38646

Breda, A., \& Lima, V. M. (2016). Estudio de caso sobre el análisis didáctico realizado en un trabajo final de un máster para profesores de matemáticas en servicio [Study of a case about the didactic analysis carried out on a final master's thesis for in-service mathematics teachers]. REDIMAT, 5(1), 74-103. https://doi.org/10.17583/redimat.2016.1955

Breda, A., Font, V., \& Pino-Fan, L. R. (2018). Criterios valorativos y normativos en la didáctica de las matemáticas: El caso del constructo idoneidad didáctica [Evaluative and normative criteria in mathematics didactics: The case of the construct of didactic suitability]. Bolema, 32(60), 255-278. https:/ / doi.org/10.1590/1980-4415v32n60a13

Castro, W. F., Pino-Fan, L. R., Lugo-Armenta, J. G., Toro, J. A., \& Retamal, S. (2020). A mathematics education research agenda in Latin America motivated by coronavirus pandemic. EURASIA Journal of Mathematics, Science and Technology Education, 16(12), em1919. https://doi.org/10.29333/ejmste/ 9277

Cervantes-Barraza, J. (2021). Una propuesta metodológica para elaborar videos creativos en clase de geometría [A methodological proposal to make creative videos in geometry class]. Cultura Educación y Sociedad [Culture Education and Society], 12(2), 79-94. https:/ / doi.org/10.17981/cultedusoc. 12.2.2021.05

Cid, E., Godino, J. D., \& Batanero, C. (2003). Sistemas numéricos y su didáctica para maestros [Number systems and their didactics for teachers]. Universidad de Granada.

Crompton, H. (2013a). Mobile learning: New theory. In Z. L. Berge, \& L. Y. Muilenburg (Eds.), Handbook of mobile learning (pp.47-57). Routledge.

Crompton, H. (2013b). A historical overview of mobile learning: Toward learner-centered education. In $\mathrm{Z}$. 
L. Berge, \& L. Y. Muilenburg (Eds.), Handbook of mobile learning (pp.3-14). Routledge.

Crompton, H., \& Burke, D. (2015). Research trends in the use of mobile learning in mathematics. International Journal of Mobile and Blended Learning, 7(4), 1-15. https:/ / doi.org/10.4018/IJMBL.2015100101

Crompton, H., \& Burke, D. (2020). Mobile learning and pedagogical opportunities: A configurative systematic review of PreK-12 research using the SAMR framework. Computers $\mathcal{E}$ Education, 156, 103945. https://doi.org/10.1016/j.compedu.2020. 103945

Crompton, H., Burke, D., \& Gregory, K. H. (2017). The use of mobile learning in PK-12 education: A systematic review. Computers $\mathcal{E}$ Education, 110, 5163.https:/ / doi.org/10.1016/j.compedu.2017.03.013

Diacopoulos, M. M., \& Crompton, H. (2020). A systematic review of mobile learning in social studies. Computers $\mathcal{E}$ Education, 154, 103911, https:/ / doi.org/10.1016/j.compedu.2020.103911

Font, V., \& Godino, J. D. (2006). La noción de configuración epistémica como herramienta de análisis de textos matemáticos: $\mathrm{Su}$ uso en la formación de profesores [The notion of epistemic configuration as a tool for analysis of mathematical texts: Its use in the training of teachers]. Educaçao Matemática Pesquisa [Mathematics Education Research], 8(1), 67-98.

Font, V., \& Salas, G. (2020). Un año de incertidumbre para la educación matemática [A year of uncertainty for mathematics education]. Bolema, 34(68), i-v. https:/ / doi.org/10.1590/10.1590/19804415v34n68e01

Godino, J. D. (2013). Indicadores de la idoneidad didáctica de procesos de enseñanza y aprendizaje de las matemáticas [Indicators of didactic suitability of the teaching and learning processes of mathematics]. Cuadernos de Investigación y Formación en Educación Matemática [Research and Training Notebooks in Mathematics Education], 11, 111-132.

Godino, J. D. (2017). Construyendo un sistema modular e inclusivo de herramientas teóricas para la educación matemática [Building a modular and inclusive system of theoretical tools for mathematics education]. In J. M. Contreras, P. Arteaga, G. R. Cañadas, M. M. Gea, B. Giacomone, \& M. M. López-Martín (Eds.), Actas del Segundo Congreso International Virtual sobre el Enfoque Ontosemiótico del Conocimiento y la Instrucción Matemáticos [Proceedings of the Second International Virtual Congress on the Ontosemiotic Approach to Mathematical Knowledge and Instruction] (pp. 1-20). Universidad de Granada.
Godino, J. D., Batanero, C., \& Font, V. (2019). The ontosemiotic approach: Implications for the prescriptive character of didactics. For the Learning of Mathematics, 39(1), 38-43.

Godino, J. D., Batanero, C., \& Font, V. (2020). El enfoque ontosemiótico: Implicaciones sobre el carácter prescriptivo de la didáctica [The ontosemiotic approach: implications on the prescriptive character of didactics]. Revista Chilena de Educación Matemática [Chilean Journal of Mathematics Education], 12(2), 47-59. https://doi.org/10.46219/ rechiem.v12i2.25

Godino, J. D., Giacomone, B., Batanero, C., \& Font, V. (2017). Enfoque ontosemiótico de los conocimientos y competencias del profesor de matemáticas [The ontosemiotic approach of the knowledge and competencies of the mathematics professor]. Bolema, 31(57), 90-113. https:// doi.org/ 10.1590/1980-4415v31n57a05

Godino, J., Rivas, H., Arteaga, P., Lasa, A., \& Wilhelmi, M. (2014). Ingeniería didáctica basada en el enfoque ontológico-semiótico del conocimiento y de la instrucción matemáticos [Didactic engineering based on the ontological-semiotic approach of mathematical knowledge and instruction]. Recherches en Didactique des Mathématiques [Research in Didactics of Mathematics], 34(2), 167-200.

Gómez, M., \& Badia, A. (2016). Exploring the use of educational technology in primary education: Teachers' perception of mobile technology learning impacts and applications' use in the classroom. Computers in Human Behavior, 56, 21-28. https:/ / doi.org/10.1016/j.chb.2015.11.023

Grant, M. M. (2019). Difficulties in defining mobile learning: analysis, design characteristics, and implications. Educational Technology Research and Development, 67(2), 361-388. https://doi.org/10. 1007/s11423-018-09641-4

Handal, B., Campbell, C., Cavanagh, M., \& Petocz, P. (2015). Characterising the perceived value of mathematics educational apps in preservice teachers. Mathematics Education Research Journal, 28(1), 199-221. https://doi.org/10.1007/s13394015-0162-y

Hernández, R., Fernández, C., \& Baptista, P. (2014). Metodología de la investigación [Investigation methodology]. McGraw Hill. http://observatorio. epacartagena.gov.co/wp-content/uploads / 2017/08/ metodologia-de-la-investigacion-sextaedicion.compressed.pdf

Homa-Agostinho, I. R., \& Oliveira-Groenwald, C. L. (2020). As tecnologias digitais da informação e comunicação como um recurso didático no currículo de matemática [The digital information and communication technologies as a teaching resource in the mathematics curriculum]. Uniciencia 
[Uniscience], 34(2), 153-170. https://doi.org/10. 15359/ru.34-2.9

Ingram, N., Williamson-Leadley, S., \& Pratt, K. (2015). Showing and telling: Using tablet technology to engage students in mathematics. Mathematics Education Research Journal, 28(1), 123-147. https://doi.org/10.1007/s13394-015-0162-y

Kyriakides, A. O., Meletiou-Mavrotheris, M., \& Prodromou, T. (2015). Mobile technologies in the service of students' learning of mathematics: the example of game application A.L.E.X in the context of a primary school in Cyprus. Mathematics Education Research Journal, 28(1), 53-78. https:// doi.org/10.1007/s13394-015-0163-x

Lai, C. L. (2019). Trends of mobile learning: a review of the top 100 highly cited papers. British Journal of Educational Technology, 51(3), 721-742. https:// doi.org/10.1111/bjet.12884

Liu, C., Zowghi, D., Kearney, M., \& Bano, M. (2021). Inquiry-based mobile learning in secondary school science education: A systematic review. Journal of Computer Assisted Learning 37(2), 1-23. https://doi.org/10.1111/jcal.12505

Morales-Garcia, L., \& Díaz-Levicoy, D. (2022). Ontosemiotic analysis of the use of multibase material in mathematics textbooks for primary education in Chile. Acta Scientiae, 24(1), 57-91. https://doi.org/10.17648/acta.scientiae.6807

Morales-Garcia, L., \& Navarro, C. (2021). Idoneidad epistémica del significado de número natural en libros de texto mexicanos [Epistemic suitability of the natural number meaning in Mexican textbooks]. Bolema, 35(71), 1338-1368. https:/ / doi.org/10.1590/1980-4415v35n71a06

Morales-Garcia, L., Navarro, C., \& Díaz-Levicoy, D. (2021). Significados del número natural en libros de texto mexicanos: Un análisis descriptivo [Meanings of the natural number in Mexican textbooks: A descriptive analysis]. Educación Matemática, 33(3), 94-120. https:/ / doi.org/10.24844/EM3303.04

Navarro, R. J., Vega, M. V., Chiroque, E., \& Rivero, C. (2018). Percepción de los docentes sobre las buenas prácticas con un aplicativo móvil para la enseñanza de matemáticas [Teachers' perception of good practices with a mobile application for the teaching of mathematics]. Educación [Education], 27(52), 8197. https://doi.org/10.18800/educacion.201801. 005

Otzen, T., \& Manterola, C. (2017). Técnicas de muestreo sobre una población a estudio [Sampling techniques on a population study]. International Journal of Morphology, 35(1), 227-232. https://doi. org/10.4067/S0717-95022017000100037

Pino-Fan, L. R., Castro, W. F., Godino, J. D. Font, V. (2013). Idoneidad epistémica del significado de la derivada en el currículo de bachillerato [Epistemic suitability of the meaning of the derivative in the high school curriculum ]. Paradigma, 34(2), 123-150.

Pino-Fan, L. R., Parra-Urrea, Y. E., \& Castro, W. F. (2019). Significados de la función pretendidos por el currículo de matemáticas Chileno [Meanings of the function intended by the Chilean mathematics curriculum]. Magis, Revista Internacional de Investigación en Educación [Magis, International Journal of Research in Education], 11(23), 201-220. https:// doi.org/10.11144/Javeriana.m11-23.sfpc

Posadas, P., \& Godino, J. D. (2021). Reflexión sobre la práctica docente como estrategia formativa para desarrollar el conocimiento didáctico-matemático [Reflection on the teaching practice as a training strategy to develop didactic-mathematical knowledge]. Didacticae: Revista de Investigación en Didácticas Especificas [Didacticae: Journal of Research in Specific Didactics], 1, 77-96. https://doi.org/ 10.1344/did.2017.1.77-96

Puentedura, R. (2014a, 28 November). SAMR in the classroom: Developing sustainable practice [Blog]. Ruben $\quad R$. Puentedura's Weblog. http:/ /www.hippasus.com/rrpweblog/archives/ 2014/11/28/SAMRInTheClassroom_DevelopingS ustainablePractice.pdf

Puentedura, R. (2014b, 12 December). Technology in education: An integrated approach [Blog]. Ruben R. Puentedura's Weblog. http://www.hippasus.com/ rrpweblog/archives/2014/12/12/TechnologyInE ducation_AnIntegratedApproach.pdf

Rico, L. (2019). Significar y comprender los sistemas numéricos [Signify and understand the number systems]. NÚMEROS Revista de Didáctica de las Matemáticas [NUMBERS Journal of Didactics of Mathematics], 100, 153-158.

Rico, L., Marín, A., Lupiáñez, J. L., \& Gómez, P. (2008). Planificación de las matemáticas escolares en secundaria. El caso de los números naturales [The planning of school mathematics in secondary school. The case of natural numbers]. Suma, 58, 723.

Rivero, C., \& Suarez, C. (2017). Mobile learning y el aprendizaje de las matemáticas; el caso del proyecto Mati-Tec en el Perú [Mobile learning and the learning of mathematics; the case of the MatiTec project in Peru]. Tendencias Pedagógicas [Pedagogical Trends], (30), 37-52. https://doi.org/ 10.15366/tp2017.30.002

Santos, J.A. (2018). Valoración de videos tutoriales de matemáticas disponibles en internet. Nuevos instrumentos para el análisis de los procesos educativos [Valuation of mathematics tutorial videos available on the internet. New instruments for the analysis of educational processes] [Doctoral thesis, Centro de 
Investigación y de Estudios Avanzados del Instituto Politécnico Nacional, México].

Sinclair, N., Chorney, S., \& Rodney, S. (2015). Rhythm in number: Exploring the affective, social and mathematical dimensions of using TouchCounts. Mathematics Education Research Journal, 28(1), 31-51. https:/ / doi.org/10.1007/s13394-015-0154-y

Sung, Y.-T., Chang, K.-E., \& Liu, T.-C. (2016). The effects of integrating mobile devices with teaching and learning on students' learning performance: A meta-analysis and research synthesis. Computers $\mathcal{E}$
Education, 94, 252-275. https://doi.org/10.1016/ j.compedu.2015.11.008

Talan, T. (2020). The effect of mobile learning on learning performance: A meta-analysis study. Educational Sciences: Theory and Practice, 20(1), 79-103. https:/ / ddoi.org/10.12738/jestp.2020.1.006

Yildiz, G., Yildirim, A., Akca, B. A., Kok, A., Ozer, A., \& Karatas, S. (2020). Research trends in mobile learning. International Review of Research in Open and Distributed Learning, 21(3), 176-196. https:/ / doi.org/10.19173/irrodl.v21i3.4804

\section{https://www.ejmste.com}

